\title{
APRENDENDO GREGO ANTIGO NO MUNDO DIGITAL DO TERCEIRO MILÊNIO
}

\section{Learning ancient Greek in the digital world of the third millennium}

\author{
Anise D' Orange FERREIRA \\ Universidade Estadual Paulista Júlio de Mesquita Filho (UNESP), Araraquara, São \\ Paulo, Brasil
}

\begin{abstract}
Resumo: Este artigo mostra como a infraestrutura digital do terceiro milênio está afetando o emprego de materiais digitais de ensino de grego antigo. Dentro de uma abordagem com foco em 'aprender fazendo', apresenta os principais pressupostos do classicismo na era digital atual apontando o trabalho de alunos e professores como um meio de produzir dados para bancos de dados de língua e cultura grega, como a Biblioteca Digital Perseu, com serviços de consulta e pesquisa, contribuindo para a formação de corpora abertos de traduções em português de textos gregos. Tal produção pode-se dar na forma de edições digitais anotadas e com traduções alinhadas. Explica-se aqui uso da plataforma Perseids para anotação de árvores sintáticas de dependência do grego antigo (treebanking) e para edição de traduções paralelas alinhadas, propondo uma atividade utilizando as suas ferramentas Arethusa e Alpheios.
\end{abstract}

Palavras-Chave: Clássicas digitais; grego de grego antigo; plataforma Perseids; árvores sintáticas; traduções alinhadas

\begin{abstract}
This article discusses how the digital infrastructure of the third millennium affects the usage of digital materials in teaching ancient Greek. Within an approach focused on 'learning by doing' this text presents the main assumptions of classicism in the current digital era, pointing out that students and their teachers are generating data through their class activities aimed at expanding data banks for Greek language and culture, such as the Perseus Digital Library, implemented with data mining services and collaborating with open corpus es which include Portuguese translations of Greek texts. That data production can be performed through digital editions with tree-bank annotations and aligned translations. The use of the Perseids platform for tree-banking annotation and translation alignment is explained, proposing an activity using its Arethusa and Alpheios tools.
\end{abstract}

Key-words: Digital classics; ancient Greek teaching; Perseids platform; treebanking annotations; aligned translations 


\section{Pressupostos do ensino de clássicas na era digital}

Línguas e literaturas antigas não são ensinadas, salvo raras exceções, no nível fundamental ou médio, nem são reconhecidas ou valorizadas por grande parte da sociedade, mesmo instruída. Diferentemente das línguas modernas, não tem uma função comunicativa imediata, abarcando o desempenho de práticas sociais. Contudo, uma língua clássica tem impacto na cultura e reside, por vezes camuflada, na origem de várias disciplinas, sejam elas das humanas, biológicas ou exatas. Ademais, vinculam-se necessariamente à profissão dos que lidam com fontes antigas. Sua aplicação em ofícios da linguagem volta-se às traduções de textos; mais além, serve à compreensão da base cultural e dos vestígios na língua, trate-se da língua materna integralmente, trate-se de terminologias específicas de área. Sendo a formação clássica encurtada aos acanhados anos universitários e demandando tempo de maturação e dedicação, sobretudo quando inclui alfabetos díspares, como o grego, ela compete em desvantagem pelo tempo dos alunos e recursos disponíveis.

Diante desse contexto, a união dos recursos digitais, especificamente, na produção de dados abertos, com os conteúdos da área, promete contemplar algumas de suas necessidades. Em primeiro lugar, as didático-pedagógicas, no sentido de auxiliar e aprimorar a leitura do texto grego por parte de estudantes em formação, por meio de recursos digitais de consulta e produção de dados. Em segundo lugar, as necessidades acadêmicas dos alunos e pesquisadores que poderão contribuir aumentando o acervo de dados eletrônicos para estudo e pesquisa. E em terceiro lugar, as sociais, ao resultar eventualmente na ampliação de acesso à comunidade dos textos gregos com as respectivas traduções. Assim, por meio de textos abertos e anotados, legíveis por máquina, pretende-se favorecer o estudo e a pesquisa, com traduções em português, alargando a diversidade do público-alvo, e criando mais oportunidades de suscitar o interesse pela área, em um círculo virtuoso.

Mas o que significa o ensino do grego na era digital do terceiro milênio? Os meios de comunicação eletrônica, que oferecem serviços ${ }^{1}$, como Youtube, por exemplo, exibem uma infinidade de vídeos contendo animações, ou professores dando instruções sobre a língua grega e a antiguidade clássica, principalmente em língua estrangeira. Todavia, o tipo de ensino ao qual me refiro se vincula a um movimento de âmbito internacional denominado 'classicismo digital', no qual se procura desenvolver uma

1 Trabalhos executados por um servidor na rede para programas clientes, em diversos protocolos (cf. Free Online Dictionary of Computing) 
ciberinfraestrutura adequada para disseminar o acesso aos textos clássicos em formato digital, tanto para fins de leitura, como também para atender a inúmeras e diversas necessidades de pesquisa na área, registrando com dados linguísticos e históricos, as línguas antigas, e desenvolvendo serviços em web e plataformas que provêem o acesso a essas línguas. Essa vinculação acontece à medida em que estudantes e cidadãos podem colaborar para o desenvolvimento de tal ciberinfraestrutura, no chamado ciclo virtuoso de aprendizagem e contribuição de dados conforme proposto por Crane et al: "estudantes contribuem com dados enquanto aprendem, e aprendem para contribuir com conhecimento" (CRANE et al. 2012, p.1). A contribuição de dados aqui se refere a colaborações específicas de edições digitais.

Para entendermos de que forma o aluno aprende contribuindo com dados, convém explicar, antes, o que são edições digitais e como elas representam um conjunto de dados. Para muitos, edições digitais são livros ou ebooks em formato PDF (portable document format) ou similares que dependem de softwares leitores específicos (Kindle, Adobe Reader, Kobo, etc). Uma edição digital, como é aqui entendida, deve ser, antes de tudo, um componente de uma base universal de dados abertos. Embora livros em PDF possam ser baixados gratuitamente na rede, esses não fazem parte de uma base universal única ou distribuída em vários servidores, de modo a que os dados possam relacionar-se. Continuam sendo obras individualizadas, como livros na prateleira de uma biblioteca, sem interconexão de uns com os outros. Para que a interação entre dados possa ocorrer, formatos universais e abertos devem ser usados, tal como o padrão TEI-XML, permitindo, assim, a distribuição da informação e a consulta por meio de serviços diversificados de data-mining ${ }^{2}$, ou mineração de dados, sob variadas interfaces. Isso marca uma diferença na concepção da produção e da disseminação do conhecimento:

A grande diferença que se instaura, portanto, no estudo e produção de conhecimento, é que os estudiosos ao fazerem sua pesquisa estão produzindo dados não como unidades isoladas e estáticas, mas como uma contribuição para um sistema mais amplo e dinâmico. $\mathrm{O}$ pesquisador precisará decidir se vai gerar um estudo monolítico que será lido por poucos, ou se vai produzir um estudo dinâmico, i.e., uma edição integrada em sistemas de conhecimento abertos, sem, contudo, desprezar o rigor e os procedimentos filológicos (FERREIRA, $2015 \mathrm{p}$. 7).

Nesse universo, há várias formas de contribuição no nível do estudante. A maioria delas se refere a um tipo de anotação manual de corpus e de alinhamento de

2 Também conhecido como mineração de dados, pesquisa de dados informação ou padrões escondidos em bases de dados. 
dados que depende do uso de plataformas e serviços desenvolvidos por classicistas digitais em parceria com cientistas da computação. Vemos também aqui uma diferença no modo de trabalhar que escapa ao controle individual, se estabelecendo como algo coletivo:

(...) os classicistas trabalham conjuntamente com os cientistas da computação, lhes indicando os parâmetros e aprendendo a inserir os procedimentos filológicos nos aparatos tecnológicos. Decorre dessa necessidade de se trabalhar em equipe que a tradição de estudos autorais pode dar lugar a estudos coletivos, com créditos distribuídos entre membros da equipe. (FERREIRA, 2015a, p.8).

Portanto, pode-se dizer que os alunos, ao mesmo tempo em que passam por uma experiência de aprendizagem, estão participando da construção colaborativa do material educacional digital. Os alunos contribuem com "dados" para um determinado serviço na ciberinfraestrutura do classicismo digital. Os dados produzidos serão eventualmente utilizados por outros estudantes, leitores ou usuários da rede. Do ponto de vista educacional, sem entrar em rotulações e discussões profundas de natureza teórica, podese dizer que essa forma de aprender e ensinar se alinha com abordagens que enfatizam o aprender fazendo, ou a aprendizagem sobre projeto, a resolução de problemas, o contexto autêntico e a participação em projetos coletivos e colaborativos (HARRINGTON, 2013; 2014; 2016; BEAULIEU, 2016). Associa-se, ainda, com pesquisa na sala de aula baseada em dados ${ }^{3}$ (LEE et al. 2013) e a técnicas heurísticas de aprendizagem ${ }^{4}$. Em uma sala de aula de língua grega no nível de graduação, com a carga horária de aulas que lhe é destinada, o estudante não pratica toda a informação gramatical existente em um livro didático a ponto de lhe capacitar a traduzir qualquer texto da literatura grega. No entanto, o aluno aprende os principais mecanismos linguísticos e deve compreender como consultar dados específicos referentes a um material empírico particular, em um universo de fontes, dentre esses, os recursos eletrônicos. Esses mecanismos linguísticos conhecidos permitem o levantamento de suposições informadas acerca de um problema e apontam caminhos para a consulta das demais fontes, de modo que o estudante consiga eliminar as hipóteses que se mostrem inadequadas para resolver a situação estudada.

\section{Nosso contexto específico de produção de dados digitais}

\footnotetext{
${ }^{3}$ Data-driven learning, em inglês.

${ }^{4}$ Técnicas heurísticas se baseiam em suposições informadas alimentando a busca de novas informações, para eliminar hipóteses erradas em direção à solução do problema.
} 
Em sala de aula utilizamos a plataforma Perseids, que contém as ferramentas de edição de alinhamento de tradução, Alpheios, com seu respectivo plugin ativado, e anotação de árvores sintáticas, treebanking, por alunos de 20 a 40 ano do curso de Letras, em disciplinas de Língua Grega e de Leitura e Tradução de Textos. A plataforma Perseids é uma plataforma colaborativa em desenvolvimento pelo Projeto Perseu (Perseus Project, Tufts University, ALMAS e BEAULIEU, 2013; ALMAS, 2014) que reúne ferramentas e serviços abertos que existiam em separado para dar suporte ao trabalho de anotação e edição de documentos no formato TEI XML. Pesquisadores interessados na pedagogia do grego e latim na Universidade Tufts têm desenvolvido e usado a plataforma para edição de manuscritos (BEAULIEU, 2016) e anotação em árvore sintática de dependência ou treebanking (BAMMAN e CRANE. 2015/2008; HARRINGTON, 2013; 2014; 2016).

Entre 2012 e 2014, dentro de um projeto financiado pelo CNPq (FERREIRA, 2015c), alunos de diferentes anos do curso de graduação de grego do curso de Letras, da UNESP em Araraquara utilizaram os editores de alinhamento de tradução e, parte deles, as árvores sintáticas da referida plataforma disponíveis separadamente pelo serviço do alpheios.net.. Esse, que continha entradas dos editores com interface em português, providas por esta autora, ainda está ativo, porém, as referidas ferramentas de edição foram aprimoradas e incorporadas a uma plataforma com recursos de login e de submissão a comitês de avaliação. A de alinhamento continuou sendo Alpheios e a de anotação em árvore sintática integrou-se a chamada Arethusa. A partir de 2015, então, nossos alunos passaram a utilizar os editores nessa plataforma.

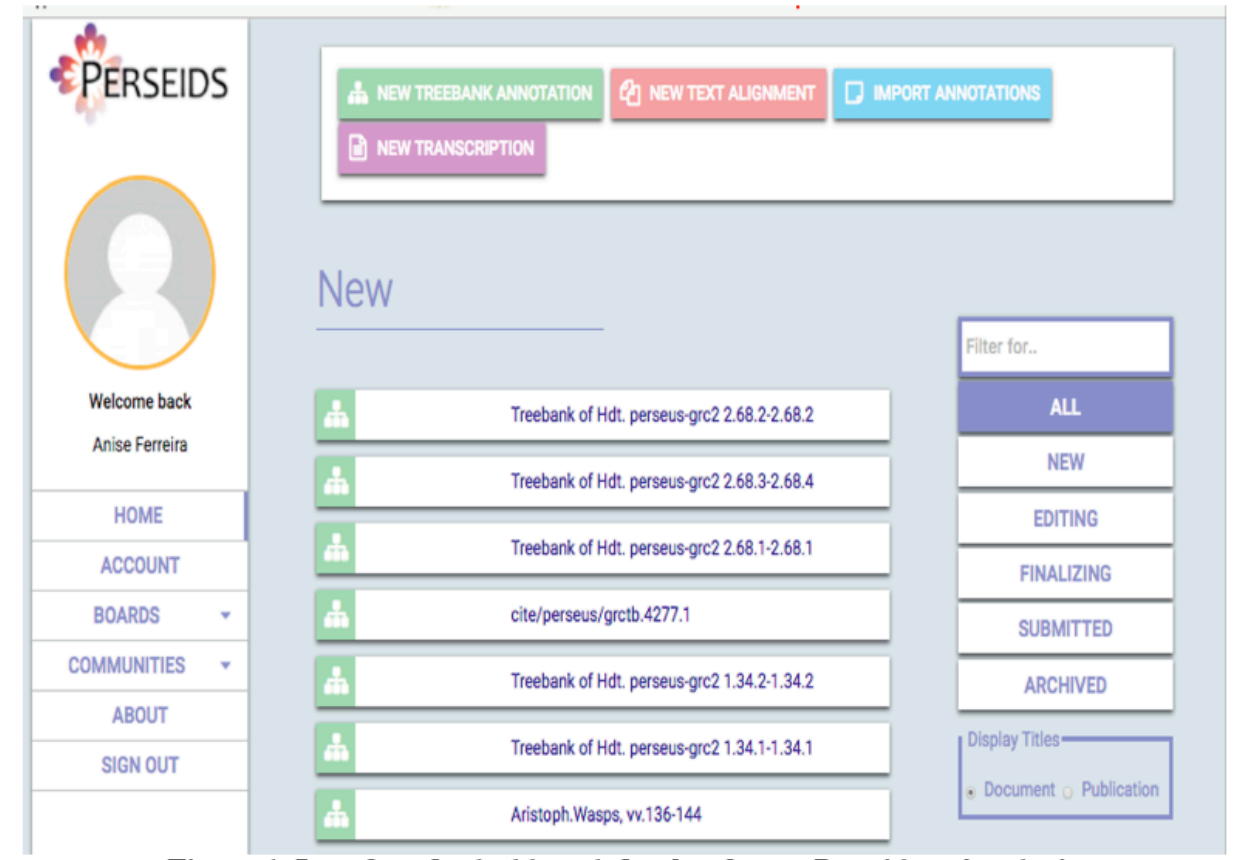

Figura 1. Interface do dashboard da plataforma Perseids após o login. 
Depois de 'logar-se', com sua conta do google, yahoo ou hotmail, o usuário ou o anotador/editor vê seu dashboard (fig.1), ou sua lista de trabalhos e links de funções. Farei referência específica à anotação de treebank e alinhamento. A figura 2 mostra os campos do editor Alpheios em que o usuário preenche com os textos a serem alinhados nas duas línguas: original, grego e tradução, português. A figura 3 exibe os textos lado a lado em que as palavras referentes a uma língua já estão associadas às palavras da outra língua, por meio de simples 'cliques' em uma e outra.

A mudança de cor indica que o alinhamento foi efetuado.

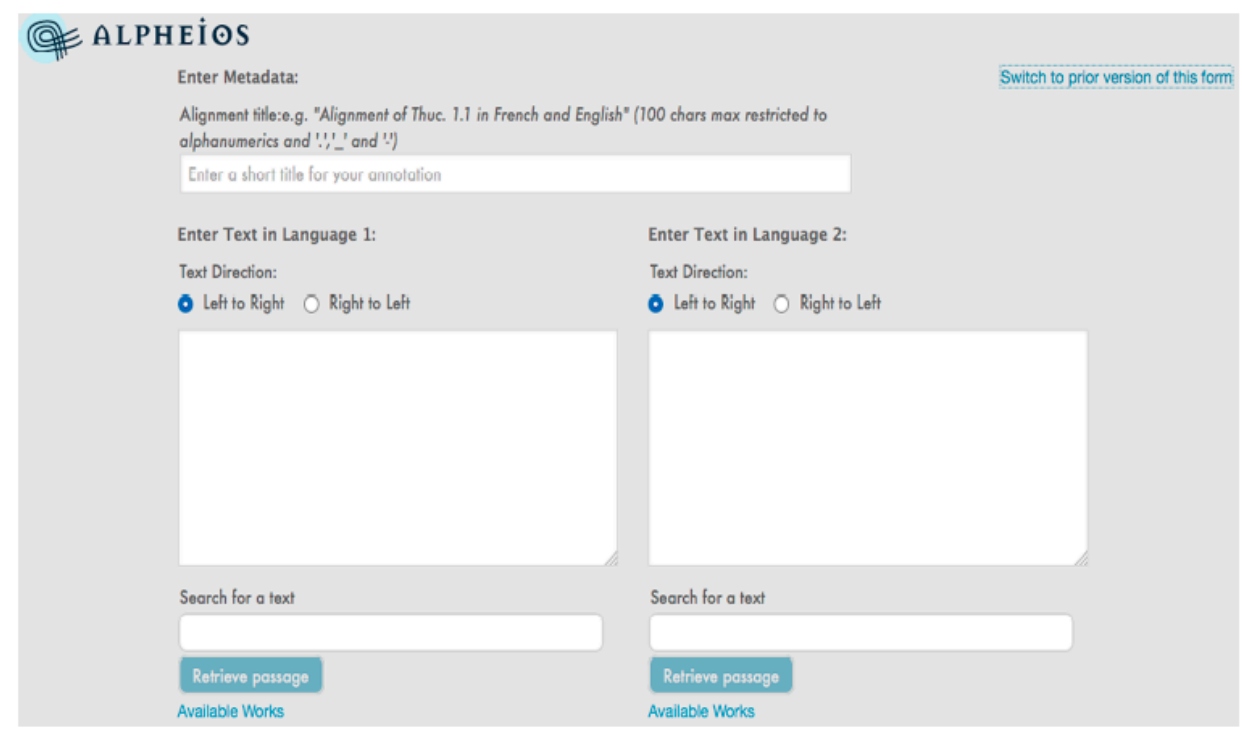

Figura 2. Interface do editor de alinhamento Alpheios dentro da plataforma Perseids, ao selecionar New Text Alignment no dashboard.

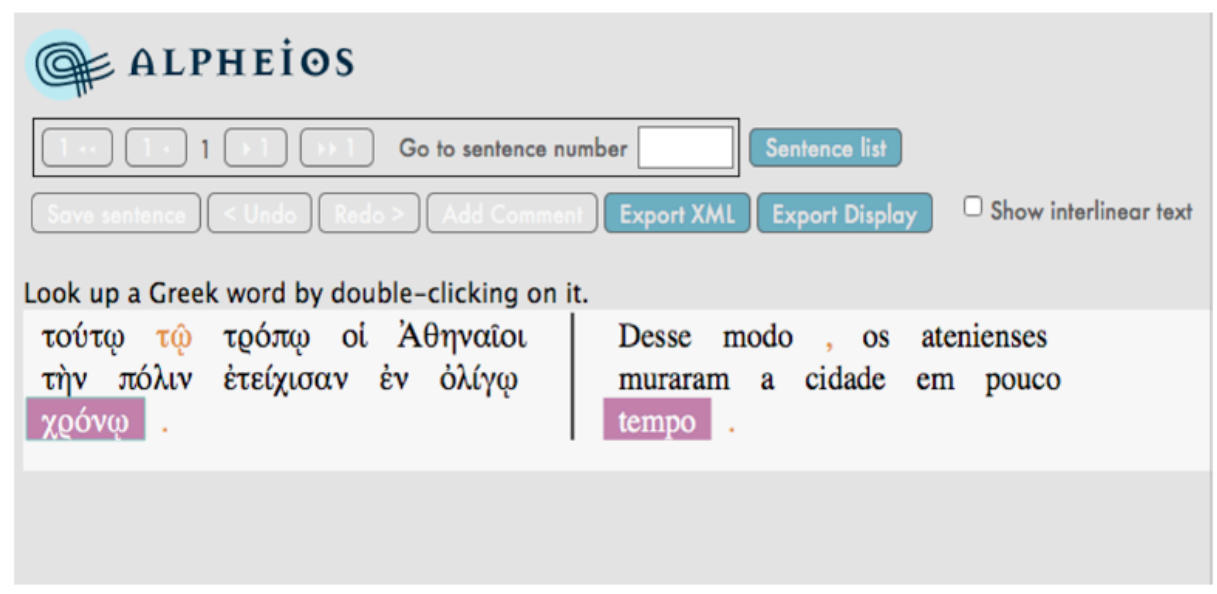

Figura 3. Interface do editor de alinhamento Alpheios, na plataforma Perseids, na etapa do próprio alinhamento 
Os editores de alinhamento e de árvore sintática de dependência do grego antigo (treebank) tem duas interfaces: uma para input ou entrada dos dados/textos e outra para a anotação propriamente dita. As figuras 4,5 e 6 indicam as respectivas interfaces. $O$ editor de treebank Arethusa é baseado no editor Alpheios com implementações para funcionar dentro de uma plataforma. Ambos contém o conjunto de etiquetas do Ancient Greek Dependency Treebank 1.0 (BAMMAN \& CRANE, 2009), baseado nas Guidelines do mesmo nome. O manual foi traduzido para o português para uso nosso ${ }^{5}$. A apresentação principal encontra-se em servidor GitHub ${ }^{6}$.

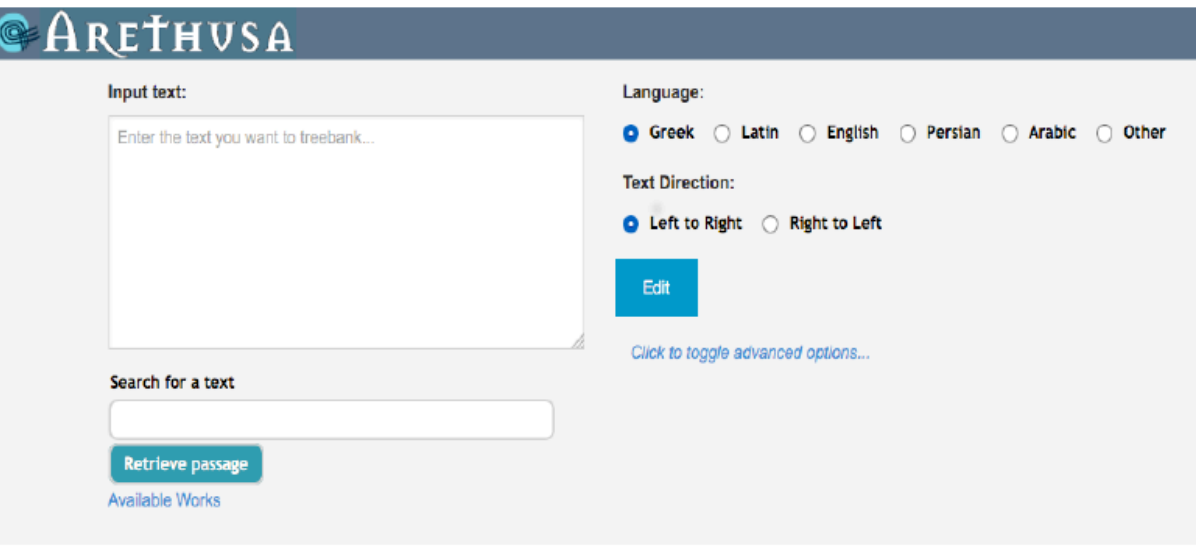

Figura 4. Interface do editor de treebanking Arethusa na plataforma Perseids, depois de selecionar New Treebank Annotation.

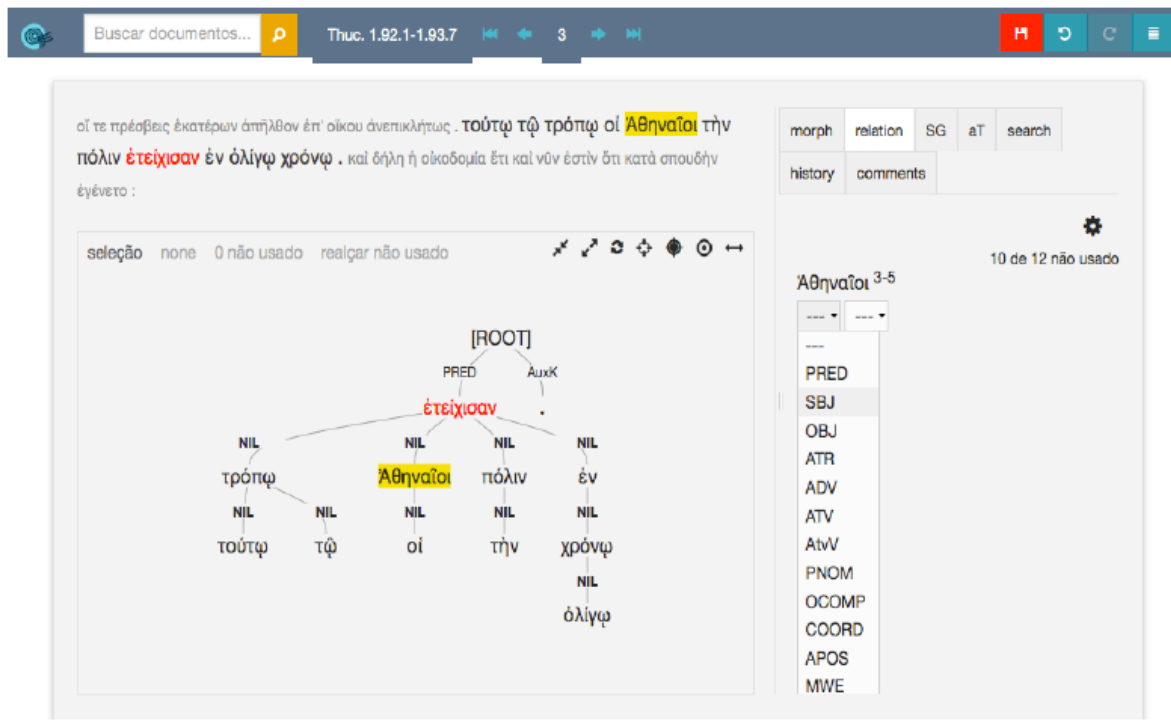

Figura 5. Interface do editor de treebank Arethusa, no momento da anotação

${ }^{5}$ Solicitar compartilhamento de arquivo em permanente atualização/revisão com a autora deste texto: https://goo.gl/dnww9A.

${ }^{6} \mathrm{https://perseusdl.github.io/treebank} \mathrm{data/.}$ 
The ESPecialist: Descrição, Ensino e Aprendizagem, Vol. 38 No. 1 jan-jul 2017 https://revistas.pucsp.br/esp CThe ESPecialist

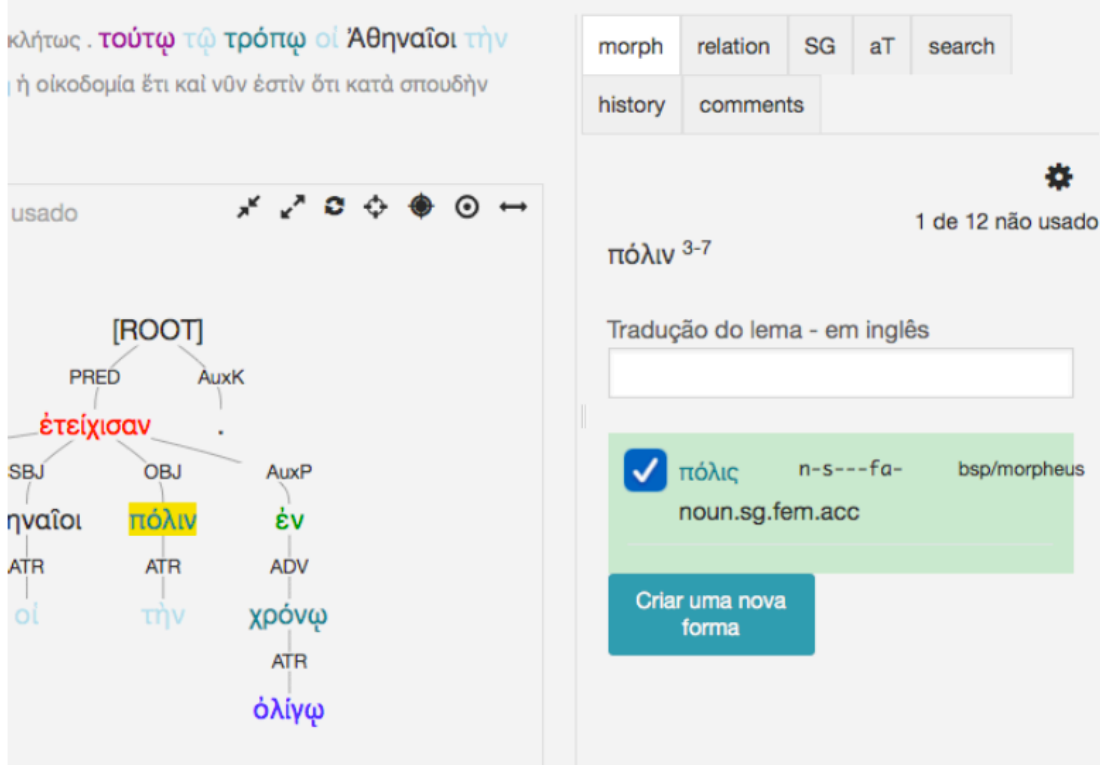

Figura 6. Interface de anotação morfológica na plataforma Perseids.

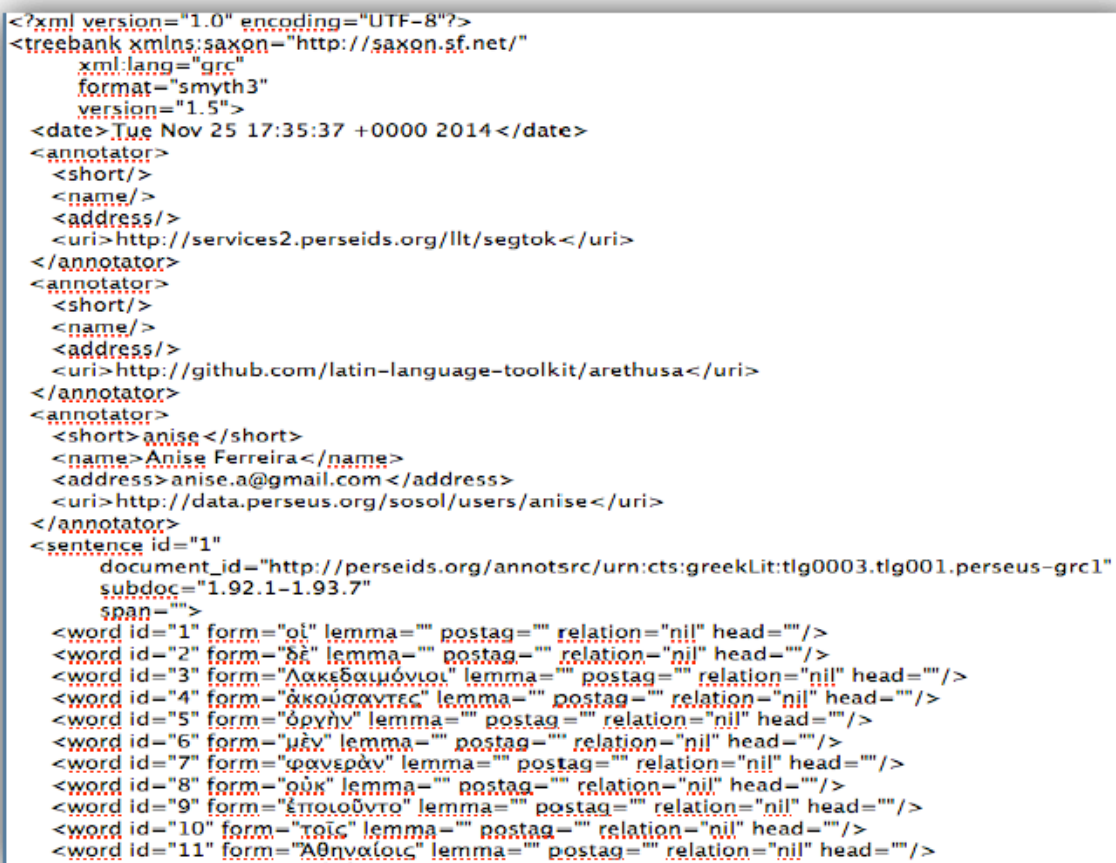

Figura 7. Parte do arquivo fonte editável em XML do treebank criado na Arethusa. 


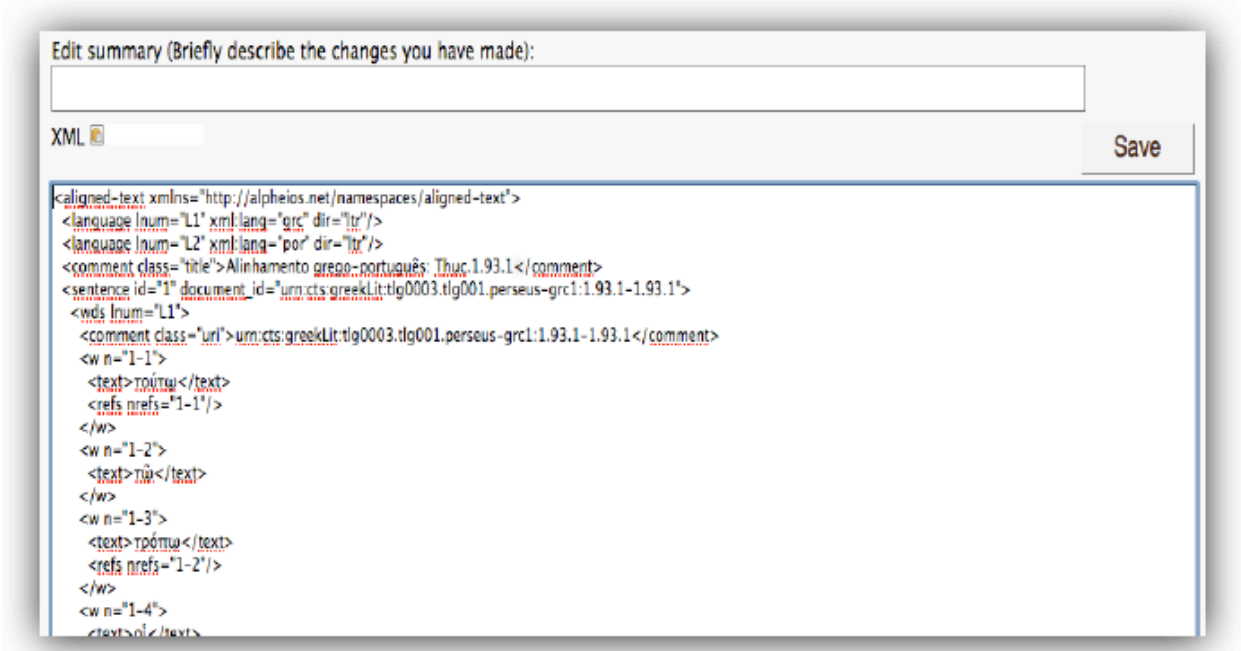

Figura 8. Parte do arquivo fonte editável em XML do alinhamento criado no Alpheios, disponível na Perseids.

As figuras 7 e 8 mostram a imagem de parte do texto produzido em XML. Em outras palavras, a interface amigável dos anotadores gera um arquivo em XML, o formato padrão para alimentar os bancos de dados que vão constituir os repositórios e aplicativos com interfaces de consulta. Observem-se os dados do anotador registrados no arquivo e a identificação de cada elemento.

A plataforma, ainda, contém um sistema de revisão, em que o anotador submete seu trabalho para um Comitê de curadores, que pode aceitar ou rejeitar o trabalho, fazendo comentários e solicitando revisão. A figura 9 mostra a interface dessa submissão.

Em publicação anterior (FERREIRA, 2015b), descrevi como o editor de alinhamento de tradução ou anotação de alinhamento de tradução pode ser utilizado como material didático para comparar diferentes traduções, observando passagens do texto de Tucídides, História da Guerra do Peloponeso, traduzidas por dois tradutores considerados autoridades no âmbito acadêmico e no editorial. $\mathrm{O}$ alinhamento obriga $\mathrm{o}$ anotador, no caso, aluno, a perceber as diferentes soluções que o tradutor encontra para frases longas ou difíceis de traduzir. Em uma das turmas de 2015, os alunos que frequentavam duas disciplinas, Leitura e Tradução de Textos- prosadores, e Língua grega III (historiografia), realizaram anotações de alinhamento de tradução em uma e anotação em treebank na outra. Um tipo de edição reforça o outro. A árvore faz perceber com mais foco a estrutura de frase grega e o alinhamento faz perceber com mais foco as escolhas lexicais e de frases da língua portuguesa.

Como observado em outra publicação (FERREIRA, no prelo), do ponto de vista do professor, a produção das anotações oferece uma oportunidade especial para observar com mais clareza os tipos de dificuldades de seus alunos, muito antes desses serem avaliados do ponto de vista formal, ainda quando realizam as tarefas, quando os 
alunos, evidentemente, apresentam suas produções com regularidade. Caso contrário, as dificuldades não serão superadas e serão descobertas somente após a avaliação formal.

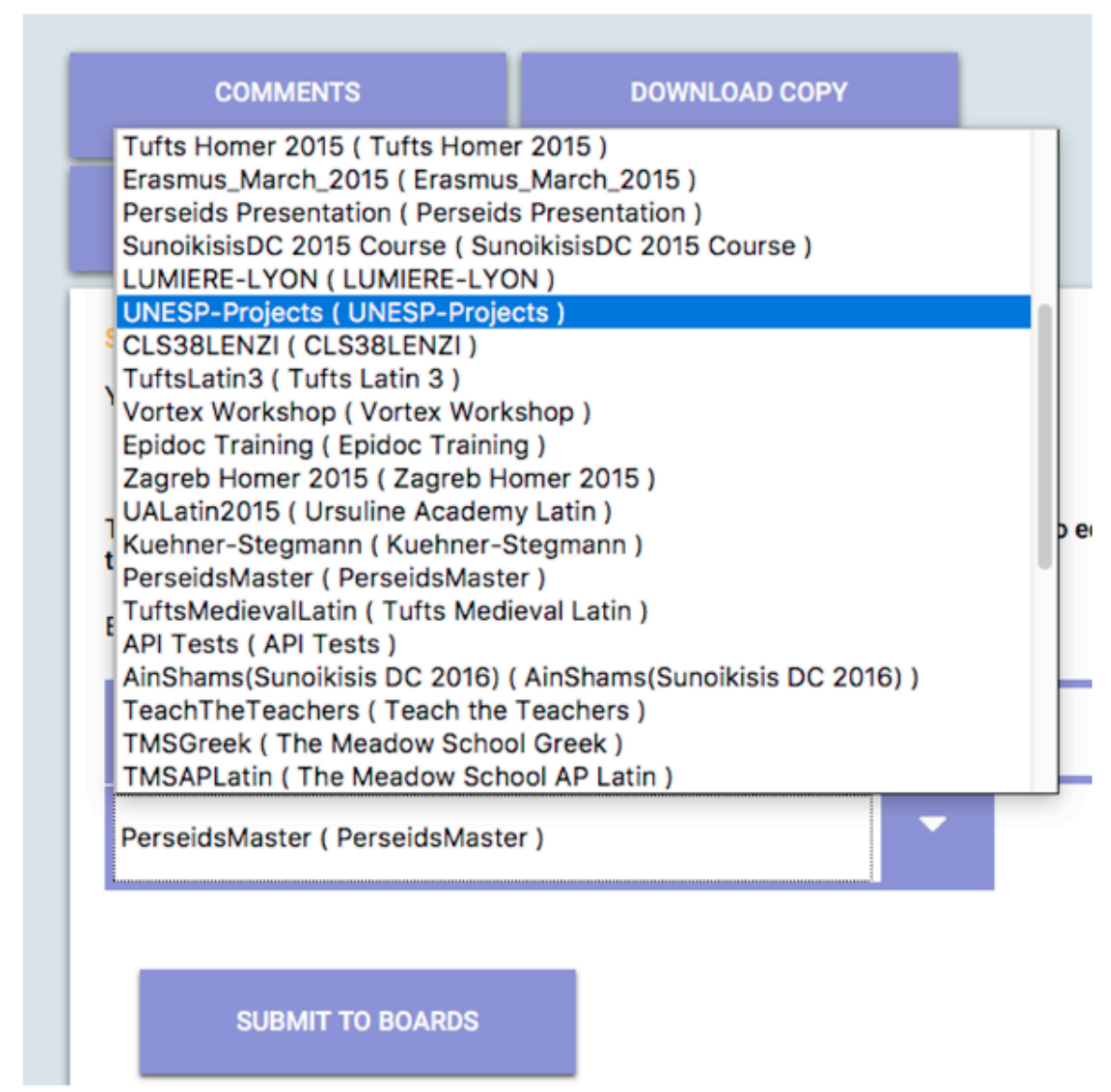

Figura 9. Interface de submissão das edições anotadas a um Board na plataforma Perseids.

O alinhamento expressa graficamente a compreensão ou a falta dela para aluno, nos níveis seja morfológico, sintático ou semântico" (FERREIRA, prelo, s.p.). Ainda:

As traduções durante o alinhamento são constantemente reavaliadas, em virtude de um esforço que se faz para aproximar, do grego, os papeis sintáticos e a ordem em português. Elas fazem ampliar a discussão sobre as leituras, traduções e estilos; parecem fazer acentuar a conscientização e memorização lexical, e portanto, das traduções, pela quantidade de repetições de alinhamento que as tomadas de decisão obrigam a fazer. Além disso, provoca uma mudança na dinâmica de sala de aula, com maior comprometimento dos alunos, e todos se transformam, de certa forma, em pesquisadores. (Ferreira, prelo, s.p.) 
Um exercício que também se pode fazer com os alunos que não estão acostumados com análise sintática é utilizar a árvore para anotar uma sentença em português. Há uma fábula de Esopo bastante conhecida que as traduções em diversas línguas são consistentes na seguinte sentença: "Um astrônomo tinha o hábito de sair de casa todas as noites para observar os astros" (ESOPO, 2013 p. $57^{7}$ ). Essa sentença poderia ser anotada com as etiquetas do $\mathrm{AGDT}^{8} 1.0$ adaptando-se as funções relativas à língua portuguesa. Em grego, o texto diz:

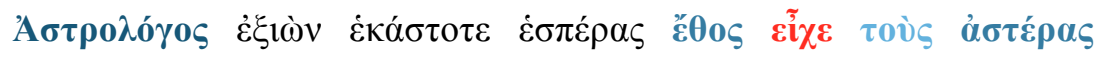
غ̇лıбколі̃баı. (Aesopica, Fabula, 40)

Um astrônomo tinha o hábito de observar os astros, saindo sempre à noite [ou, quando saía sempre à noite]. (tradução de serviço minha).

[Alternativa: Um astrônomo, que saía sempre à noite, tinha o hábito de observar as estrelas. ]

Um astrônomo tinha o hábito de sair de casa todas as noites para observar os astros" (ESOPO, 2013 p. 57)

Um detalhe gramatical das traduções acima se refere, primeiramente, a $\dot{\varepsilon} \kappa \alpha ́ \sigma \tau o \tau \varepsilon$

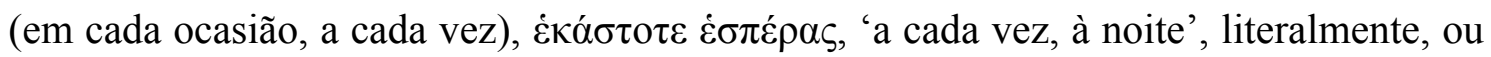

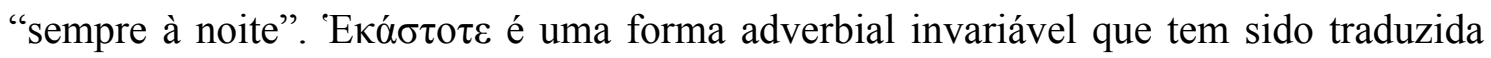
nesta frase por uma forma flexionada, no plural, 'todas', em várias traduções de línguas

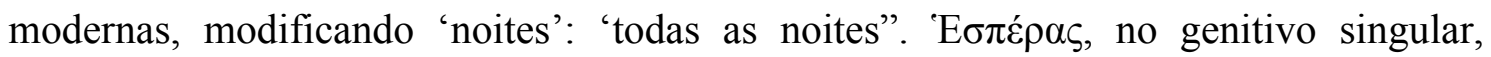
indica o momento de tempo em que se está, significando 'à noite' (SMYTH, 1920 $\S 1444)$. Mas podemos considerar que 'toda noite' pode expressar bem a ideia de repetição 'a cada vez, à noite'. Não há um estranhamento nesta adaptação de tradução à língua alvo. Além disso, existe um registro alternativo, em outra fonte, das formas $\dot{\varepsilon} \kappa \alpha ́ \sigma \tau \eta \nu ~ \varepsilon \delta \tau \varepsilon \dot{\varepsilon} \rho \alpha$ (cf. nota 12), no acusativo singular, que conotaria duração ('saindo por toda noite'). Sintaticamente, levaria a uma árvore diferente, na qual o que é um advérbio nas edições teubneriana e augustana desempenha, na tradução, um papel de qualificador, determinante ou atributo da palavra 'noite' dependendo dela na árvore.

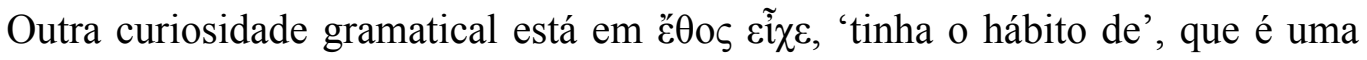
expressão usada com o complemento no infinitivo (LIDELL \& SCOTT, 1940;

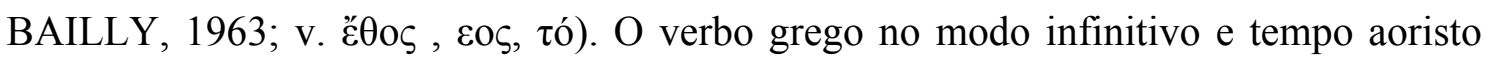

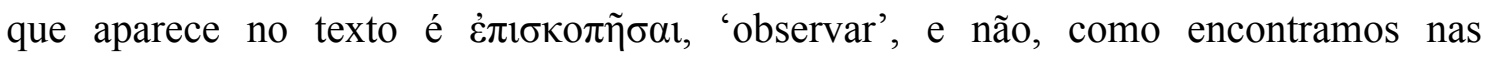

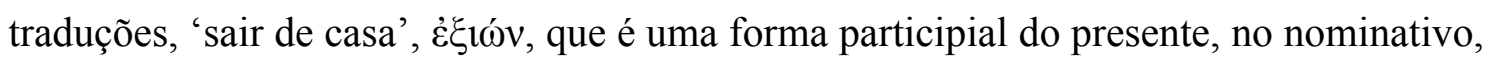

\footnotetext{
${ }^{7}$ Trad. de M. Celeste C. Dezotti.

${ }^{8}$ Ancient Greek Dependency Treebank Guidelines 1.0
} 


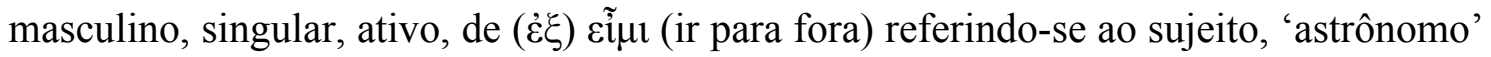
e significaria, literalmente, 'saindo'. O particípio grego pode ter várias funções. Aqui, não deveria completar o sentido da expressão 'ter o costume de', já que o texto fornece um infinitivo que pode cumprir essa função. Em outras palavras, a oração participial pode ser entendida como uma circunstância do verbo 'observar' ou seja, 'um astrônomo tinha o hábito de observar os astros, quando saía à noite'. Mas os tradutores de algumas línguas modernas concordaram com a ideia de que o astrônomo tinha o hábito de sair todas as noites com a finalidade de observar os astros ${ }^{9}$, de modo que o particípio 'saindo' seria o complemento de 'ter o hábito de'. O grego, todavia, parece trazer, de fato, 'tinha o hábito de observar os astros'. Neste caso, em particular, embora não se altere a ação do sujeito e o sentido do seu contexto na fábula, veremos ser difícil obter uma árvore sintática de dependência que representasse as traduções publicadas nessas línguas modernas, uma vez que as gramáticas não sustentam tal representação ${ }^{10}$. Muitos complementos de verbos são dados no particípio. No entanto, aqui, a expressão 'ter o hábito ou costume de' precisaria ter algum registro de um complemento no particípio e não no infinitivo, alguma edição copiando o verbo 'sair' com flexão no infinitivo, ou

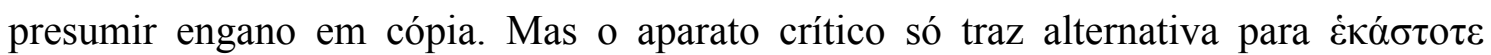
$\dot{\varepsilon} \sigma \pi \dot{\varepsilon} \rho \alpha \varsigma^{11}$. Mesmo que subentendêssemos a forma verbal no perfeito, que significa 'estar acostumado a', Eí $\omega \theta \alpha$, ou o verbo $\dot{\varepsilon} \theta$ í $\zeta \omega$, de mesmo sentido, o modo do complemento registrado nos dicionários seria o infinitivo e no corpus do TLG (Thesaurus Linguae Graecae) ${ }^{12}$.

Essas relações ficam muito mais evidentes quando se examina a árvore e se faz o alinhamento de tradução. Primeiramente, as figuras 10a e 10b exibem como poderiam ser representadas essas sentenças por árvores sintáticas de dependência em português, levando-se em conta que as etiquetas são do tagset do grego e que, em português, precisamos acrescentar preposições (AuxP), conjunção (AuxC) e não há artigo indefinido em grego, recebendo a mesma etiqueta de um artigo definido. Além disso, a contração do artigo com a preposição, à, leva o anotador a priorizar a função da preposição sobre o artigo nas árvores.

\footnotetext{
${ }^{9}$ Editorial Gredos, 1985: Un astrónomo tenia la costumbre de salir todas las noches a observar las estrellas. Worthington, 1884: An Astronomer used to walk out every night to gaze upon the stars. Chambry 1927: Un astronome avait l'habitude de sortir tous les soirs pour examiner les astres.

${ }^{10}$ Cf. Dic. Liddell \& Scott: $\ddot{\varepsilon} \theta$ o + inf.

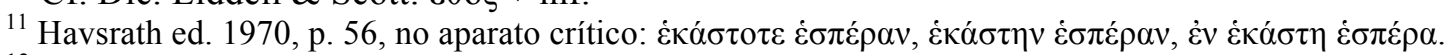

${ }^{12}$ Cf Dic. Cunliffe, $\ddot{\varepsilon} \theta \omega$. Cf. DGE e Liddell \& Scott: $\dot{\varepsilon} \theta \omega$, $\dot{\varepsilon} \theta i \zeta \zeta \omega$; cf concordâncias no TLG para os respectivos lemas.
} 


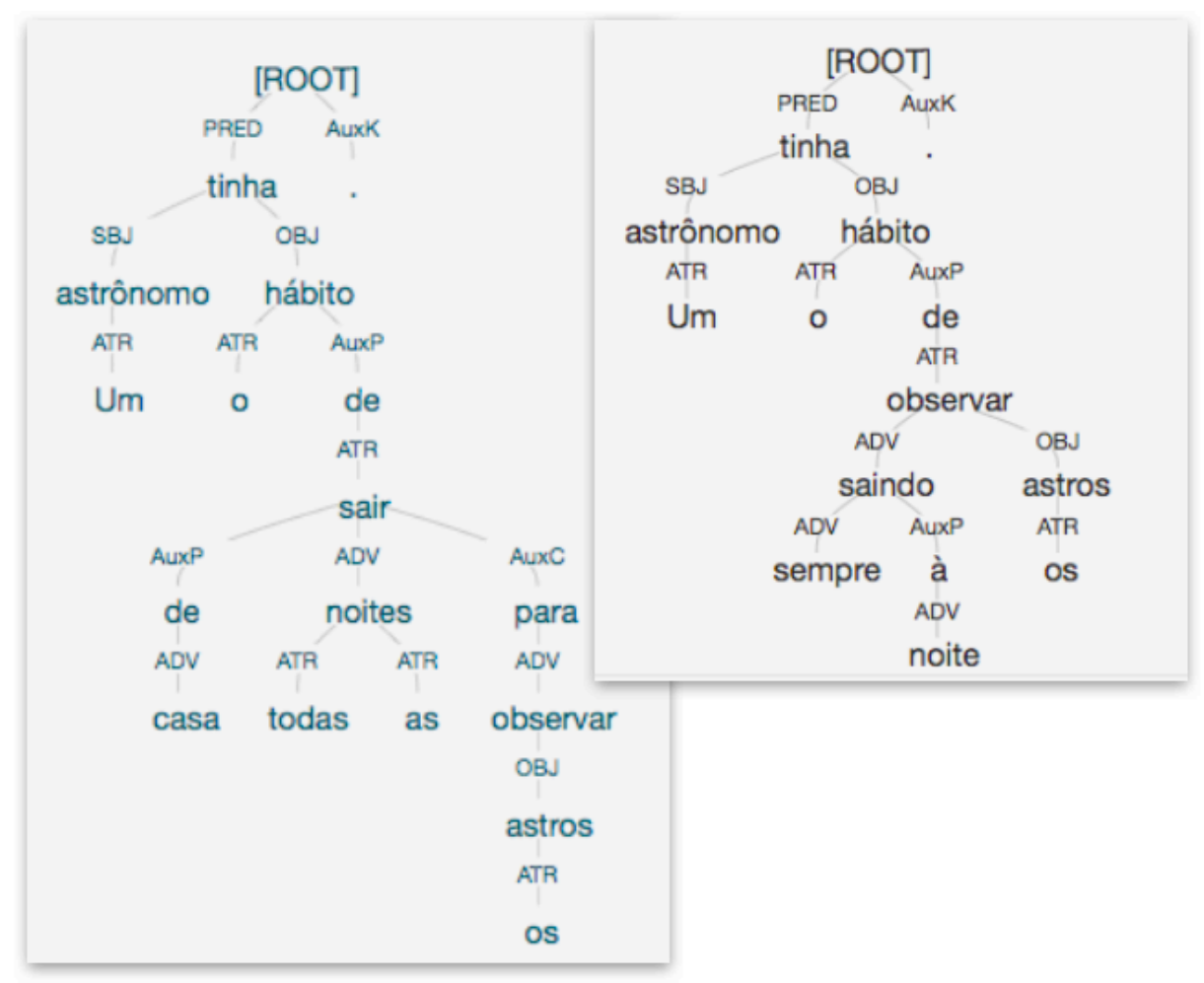

Figuras 10 a e 10 b. Hipóteses de árvores sintáticas feitas com base nas traduções em português.

Em seguida, observe-se, que a oração 'saindo toda noite' (i.e. saindo sempre ou regularmente à noite), cujo verbo está no particípio ativo grego que corresponde ao gerúndio em português, pode supor tanto uma característica do sujeito, o astrônomo, de sentido atributivo correspondente a uma oração relativa:"“que saía toda noite", principalmente por causa da posição, como pode supor um sentido circunstancial: “quando saía toda noite”, ou "ao sair toda noite". Na primeira interpretação, o verbo no particípio recebe a etiqueta ATR, de atributo (fig. 11a). Na segunda, recebe a etiqueta ADV, de adverbial, segundo o manual do AGDT. (fig. 11b).

As eventuais diferenças, quando dentro de um grande corpus ou base de dados, não representam um problema, pois diferentes leituras são esperadas (BAMMAN e CRANE, 2015[2008]) e poderão ser medidas em termos estatísticos.

Os particípios não são os únicos casos em que pode haver ambiguidade na análise e provocar dúvidas no processo de anotação. Nessas circunstâncias, professores e alunos podem aprofundar-se nas informações filológicas e gramaticais sobre os textos trabalhados, consultando outras obras, edições comentadas disponíveis e diversas gramáticas para chegarem a uma decisão mais bem informada. Pois sabemos que no uso 
The ESPecialist: Descrição, Ensino e Aprendizagem, Vol. 38 No. 1 jan-jul 2017 https://revistas.pucsp.br/esp CThe ESPecialist

literário da língua grega encontramos variações lexicais e sintáticas, em função das edições, gênero, da época e do autor. Também podem consultar árvores de corpora digitais de grego e latin já anotados em treebank ${ }^{13}$.

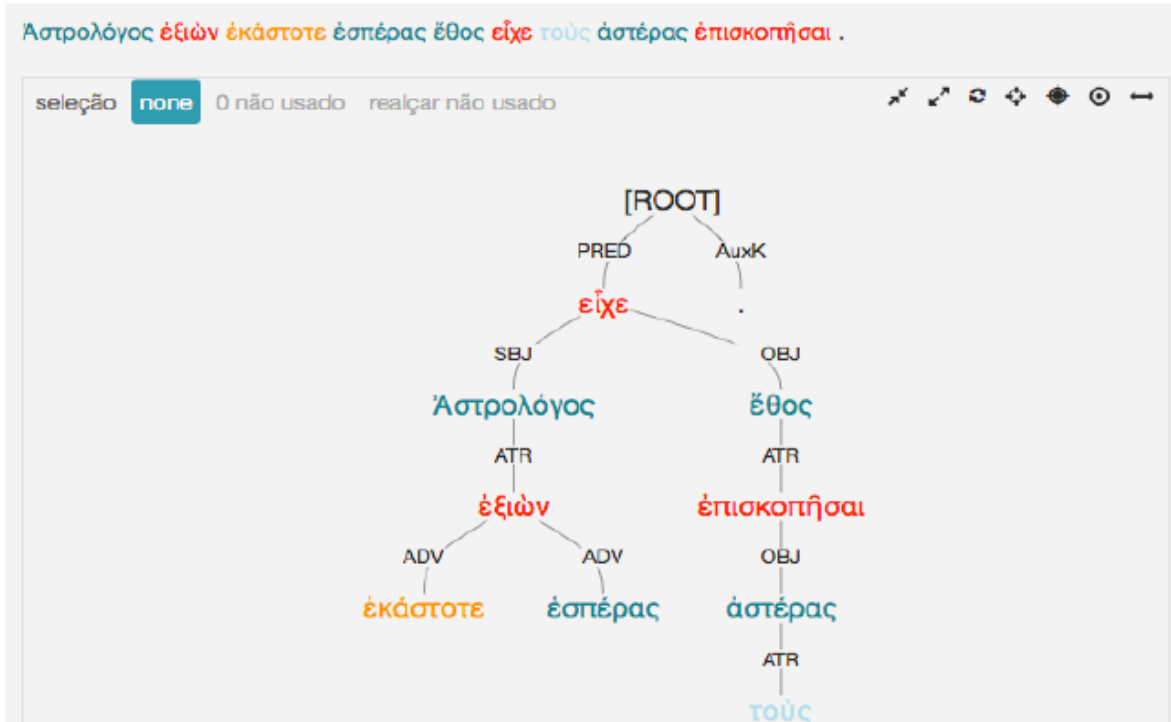

Figura 11a. Árvore anotada com o editor Arethusa, exibindo um particípio entendido como ATR, segundo o manual do AGDT: Um astrônomo que saía...

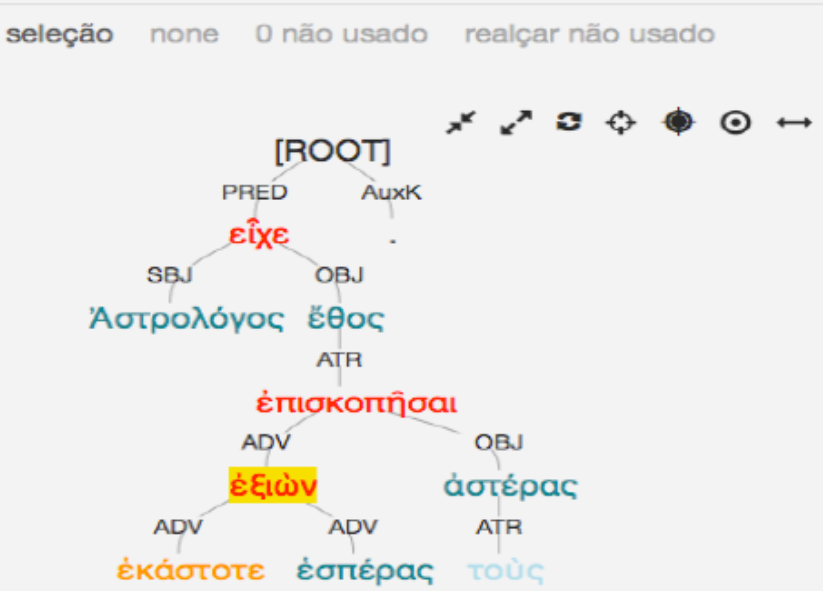

Figura 11b. Árvore anotada com o editor Arethusa, exibindo um particípio entendido como ADV, segundo o manual do AGDT: Um astrônomo, tinha o hábito de...quando saía...

${ }^{13}$ Annis Query Tool - Perseus Latin and Ancient Greek Treebank http://annis.perseus.tufts.edu/ e Clarin Tündra Perseus: http://weblicht.sfs.uni-tuebingen.de/TundraPerseus/ 
Com o alinhamento, apenas, o estudante consegue descobrir o vocabulário correspondente em grego e em português, mas não tem, necessariamente, elementos para julgar a decisão sintática adotada pelo tradutor se já estiver de posse de uma tradução. Mas pode comparar diferentes traduções. As figuras 12a e 12b mostram como seriam ambas as traduções alinhadas exibindo o modo interlinear.

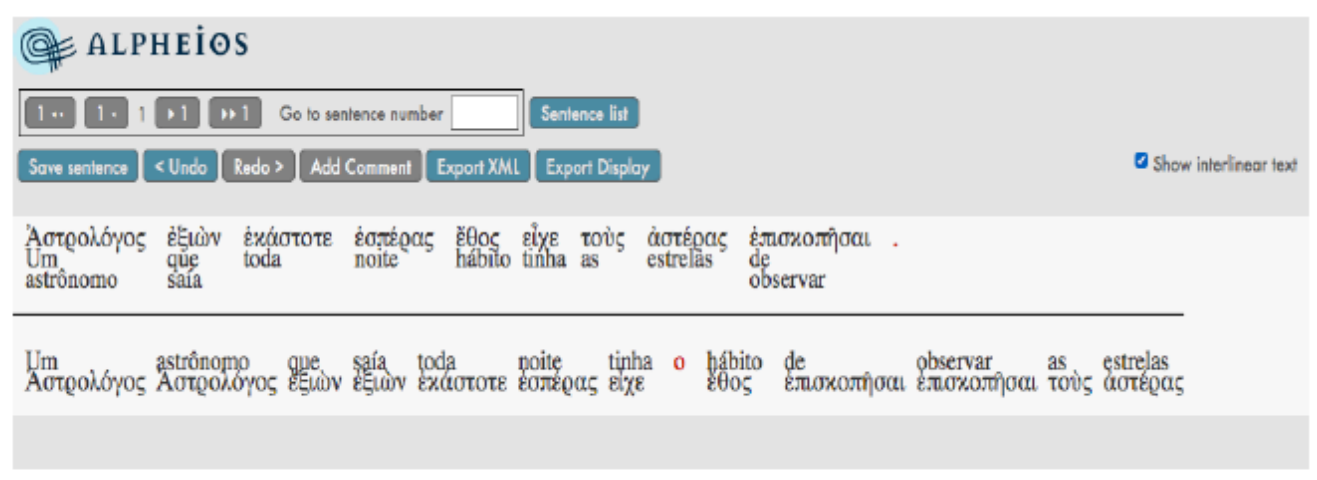

Figura 12a. Alinhamento no modo interlinear com tradução de serviço, não publicada, que segue uma das árvores referentes à fábula do Astrônomo.

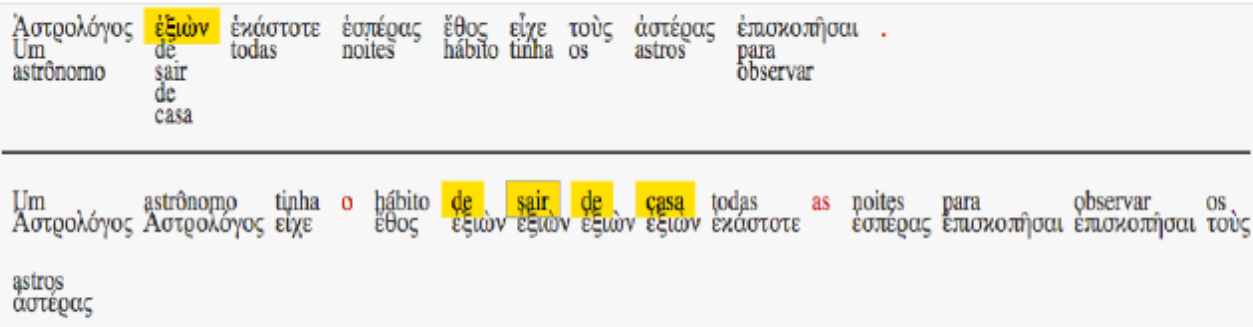

Figura 12b Alinhamento no modo interlinear com tradução publicada da sentença referente à fábula do Astrônomo.

\section{Proposta de atividade com o material educacional digital}

Com base na exposição anterior, o aluno e professor deverão produzir anotações sintáticas em árvores de dependência (AGDT) ou treebanking e uma tradução alinhada do mesmo texto, seguindo os passos abaixo indicados, em um ambiente com computador ligado à Internet e com navegador Firefox (até versão max. 44).

1) Selecionar o texto grego. Para esta atividade, abrir a fábula de Esopo da Camela Dançarina, no site da Bibliotheca Augustana: https://www.hsaugsburg.de/ harsch/graeca/Chronologia/S ante06/Aesop/aes m182.html 
(a) Abrir no navegador Firefox versão até 44, para instalar o plugin do Alpheios (alpheios.net) para obter análise automática morfossintática, clicando sobre cada palavra grega da primeira sentença.

(b) Como alternativa ao plugin do Alpheios, copiar a primeira sentença da fábula no lematizador automático no site Eulexis, http:/outils.biblissima.fr/eulexis/ para obter todo o vocabulário com classificação morfossintática.

2) Abrir a plataforma Perseids (perseids.org) e fazer login com uma conta do google, yahoo ou hotmail.

(a) Na plataforma, o aluno vê a área chamada dashboard (fig.1), onde vão ficar os elementos trabalhados como listas, em colunas, conforme o tipo de trabalho (alinhamento, tradução, edição, etc.); depois, vai abrir o editor New text alignment: em um dos campos 'colar' o texto grego e indicar a língua grega nas configurações (fig.2). No outro campo, preencher com uma tradução existente ou a ser produzida, marcando a opção de língua: Português. Apertar botão Align. Para alinhar as palavras gregas com sua correspondente em português, clica-se primeiro em uma das palavras e, depois na correspondente em outra língua (fig.3). É possível desfazer o link clicando-se novamente sobre a mesma palavra. O aluno deve salvar a sentença alinhada usando o botão apropriado: save sentence (fig.3). Nessa mesma página de execução do alinhamento, há um botão para exportar o arquivo alinhado em XML ou exportá-lo em XHTML, que permite a visualização, o export display, i.e., o arquivo pode ser baixado no próprio computador e aberto no navegador para se visualizar o alinhamento (fig.3). A visualização do alinhamento se dá com o passar do mouse sobre as palavras ou pelo modo de visualização interlinear. O botão sentence list faz o editor de alinhamento voltar a lista de sentenças no alinhamento (fig.13). Na página sentence list há outros links de gerenciamento, como change title, para mudar o nome que seja fácil de localizar depois, inserção de comentário, edição direta no arquivo XML. O link home aponta de volta para o dashboard. Para essa operação de alinhamento de tradução, o aluno precisará consultar os recursos que fornecem informação sobre o léxico - dicionário com um analisador morfológico automático (Eulexis, Perseus, Alpheios, Diogenes, etc.). O professor acompanha o trabalho interrogando o aluno sobre as hipóteses que levanta, justificando as hipóteses. A realização de alinhamentos com traduções diferentes do mesmo texto grego promove vários insights sobre mecanismos de tradução e usos lexicais da língua grega. 
Treebank of Hdt. perseus-grc2 1.34.1-1.34.1 (FROM ANNOTATION PUBLICATION/201723/7)

IDENTIFIER CITE/PERSEUS/GRCTB.4273.1

OVERVIEW EDIT EDIT XML PREVIEW DOWNLOAD COPY COMPARE CHANGE TITLE HISTORY

(6) Select a sentence to Edit

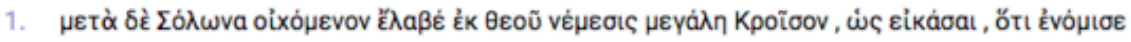

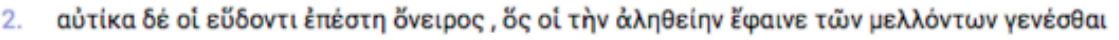

Figura 13. Interface exemplo de uma lista de sentenças na plataforma Perseids

3) Para a anotação em treebank, professor e aluno precisarão ler o manual AGDT, com exemplos de anotação, para saberem quais etiquetas podem utilizar na anotação. Depois, na plataforma Perseids, para produzir a árvore, deverão clicar em New treebank annotation (fig.1). Abre-se o editor Arethusa, onde há o campo para a inserção das sentenças (fig.4). Podem 'colar' a sentença sugerida ou, se quiserem, um conjunto de sentenças. Porém, para que um grupo de sentenças completas possam ser montadas, elas precisam ficar em linhas separadas. A divisão básica da sentença é marcada pelo ponto, mas pode ocorrer por outros sinais de pontuação, como vírgulas. A divisão em sentenças (parsing) não é feita automaticamente, a menos que se selecione uma seção do corpus disponível no próprio servidor, usando o botão Retrieve passage (fig.4). Não havendo a divisão prévia, o professor deve orientar o aluno na separação das sentenças, por meio dos sinais de pontuação e conferência dos verbos, de modo que cada uma fique em uma linha separada, com quebra de linha. Cada árvore contém uma única sentença completa, composta por um único PRED (ver manual), ou verbo finito, a menos que seja um período coordenado. Logo depois de inserir a(s) sentença(s), deve-se selecionar a língua: Language: Greek. Nas opções avançadas, pode-se escolher o sistema de tagset para anotação. O que utilizamos é o AGDT, a primeira opção ou default, que contém anotação das etiquetas sintáticas (aba relation e de anotação morfológica, aba morph) (fig. 5). Entre as duas anotações, aconselho a começar pela anotação morfológica (morph) do AGDT pela qual se define a classe gramatical e flexão da palavra, atribuindo uma cor. Caso a classificação correta não esteja disponível na 
lista oferecida pelo próprio programa, o editor pode acrescentar a forma e a flexão correta. Um sistema de anotação complementar é o SG ${ }^{14}$ (Smyth Grammar), proposto por Celano ${ }^{15}$, cujo manual de anotação pode ser obtido no próprio site do autor e que inclui as etiquetas AGDT. Uma aba importante é aT, de artificial token, usada para permitir inserir na árvore um verbo elíptico, do qual outros elementos da sentença são dependentes. No grego, é comum a elipse do verbo 'ser' mas são necessários na construção das árvores. Com a inserção do aT, o verbo aparece na cor vermelha e em tamanho menor.

4) Se o professor tiver um projeto e quiser participar de forma colaborativa com o projeto Perseids, anotando textos sem restrições de direitos, com seus alunos em sala de aula ou em grupos de estudo, pode solicitar aos responsáveis pela plataforma a abertura de um Board próprio para efetuar a curadoria dos trabalhos realizados, através da plataforma. Quando considerar que a anotação estiver correta e pronta, o curador do seu board aceita e finaliza a submissão para outra etapa do fluxograma.

É importante lembrar que a plataforma está equipada para aceitar anotações em treebank também do Latim, Árabe e Persa. Os alinhamentos de tradução podem ser feitos com pares de textos em quaisquer idiomas. Apenas farão parte da base de dados os textos de línguas históricas.

Essas atividades apontam ambiguidades, suscitam dúvidas linguísticas, opções de tradução e muita discussão. Essas atividades propiciam a formação de grupos e incentivam novas pesquisas. A proposta de anotação sintática AGDT não é definitiva, nem é a única forma de se anotar a sintaxe grega em recursos digitais. Pode ser aprimorada por novos projetos. Da mesma forma, os textos alinhados podem ser enriquecidos por outras formas de anotação. Os projetos de anotação de corpus estão em franca expansão e são abertos à contribuição de interessados, tanto no âmbito filológico, como no computacional. Uma das metas é associar as edições com tradução alinhada a outros tipos de anotações.

\section{Referências Bibliográficas}

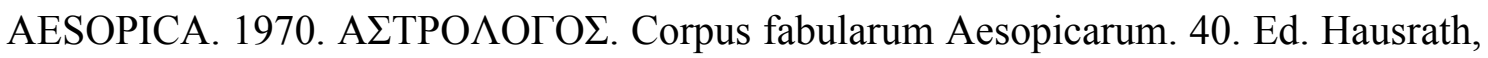
A., Hunger, H. Leipzig: Teubner.

ALMAS, B.; Beaulieu, M. C. 2013. Developing a New Integrated Editing Platform for Source Documents in Classics. Literary \& Linguistic Computing DOI $=10.1093 / 1 \mathrm{c} / \mathrm{fqt} 046$. Disponível on-line:

\footnotetext{
${ }^{14}$ Aparece na aba da figura 5.

${ }^{15}$ Celano, Giuseppe G. A. 2014. Guidelines for the annotation of the Ancient Greek Dependency Treebank 2.0.

https://github.com/PerseusDL/treebank data/blob/master/AGDT2/guidelines/Greek guidelines.md
} 
http://1lc.oxfordjournals.org/cgi/content/full/fqt046?ijkey=poDdgloq53EQiLY\&keytype $=$ ref

, Bridget. 2014. The Perseids Platform for Collaborative Editing and Annotation: A Technical Summary. CAMWS: 110th annual meeting, Waco, April 2014. Disponível on-line: https://camws.org/meeting/2014/abstracts/panels/012.Perseids/Perseids.3.pdf

Bridget; BEAULIEU, Marie-Claire; HÖFLECHNER, Gernot Perseids and Arethusa: Building Tools that Build Digital Humanists. In Digital Humanities 2015: Global Digital Humanities, Sydney, Australia : University of Western Sydney, 2015. Disponível online: http://dh2015.org/abstracts/xml/ALMAS Bridget May Perseids And Arethusa Buil ding/ALMAS Bridget May Perseids And Arethusa Building Tools.html

BAILLY, A. 1963. Dictionnaire Grec-Français. Paris: Hachete.

BAMMAN, D. $\varepsilon$ CRANE, G. 2009. Guidelines for the syntactic annotation of Ancient Greek treebanks,version 1.1. Tech. rep., Tufts Digital Library, Medford.

2015 [2008]. Linguística de corpus, treebanks, e reinvenção da filologia In Ferreira (org.) Introdução aos textos clássicos na era digital do terceiro milênio. Araraquara: Letraria.

BEAULIEU, Marie-Claire. 2016. Valid and verified undergraduate research. Apresentação no evento "Unlocking Digital Humanities IV". Comunicação oral. Organizado pela Cadeira Alexander Von Humboldt da Universidade de Leipzig. Disponível online: https://youtu.be/ypUKtYkI0F0

Marie-Claire, 2014. Teaching Classical Mythology with a Dynamic Syllabus: A New Approach to an Old Course. CAMWS: 110th annual meeting, Waco, April 2014. Disponível on-line: https://camws.org/meeting/2014/abstracts/panels/012.Perseids/Perseids.1.pdf BERTI, Monica \&Almas, Bridget Perseids Collaborative Platform for Annotating Text Re-Uses of Fragmentary Authors . In DH-CASE 2013: Collaborative Annotations in Shared Environments: metadata, vocabularies and techniques in the Digital Humanities, Florence, Italy : ACM Digital Library, 2013. Disponível on-line: http://www.fragmentarytexts.org/wp-content/uploads/2013/09/DH-Case-2013-

Paper.pdf

CRANE, Gregory; ALMAS, Bridget; BABEU, Alison; CERRATO, Lisa; HARRINGTON, Matthew; BAMMAN, David; DIAKOFF, Harry. 2012. Student Researchers, Citizen Scholars and the Trillion Word Library. In Proceedings of the 12th ACM/IEEE-CS Joint Conference on Digital libraries (JCDL 2012), pages 213-222, Washington, D.C. : ACM Digital Library, 2012. Disponível on-line: http://dl.tufts.edu/catalog/tufts:PB.001.001.00023

ÉSOPE. 1927. Fables. Éditées et traduites par Émile Chambry. Paris: Les Belles Lettres.

ESOPO. 2013. O Astrônomo. Fábulas Completas. Perry n. 40/ Chambry n. 65. Trad. Maria Celeste Consolin Dezotti. São Paulo: Cosac Naify.

. 1985. El astrónomo. Ch. 65. Fábulas de Esopo. Vida de Esopo. Fábulas de Bábrio. Introd. C. G. Gual; Introd., trad. e notas: Bádenas de La Peña e López Facal. Madrid: Editorial Gredos 


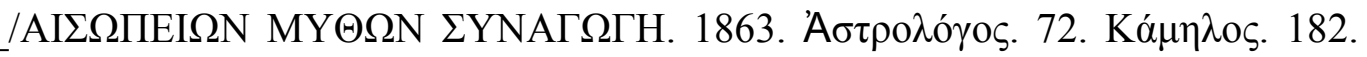
Fabulae Aesopicae collectae ex recognitione Caroli Halmii. Lipsiae: Teubneri. Disponível on-line na Bibliotheca Augustana.

FERREIRA, Anise D'O. 2015a. Introdução. In Ferreira (org). Introdução aos textos clássicos na era digital do 3 o milênio. Araraquara: Letraria.

, Anise D'O. 2015b. Traduzindo e produzindo dados abertos nas letras clássicas digitais. In Santos e Oliveira (orgs) Estudos Clássicos e seus desdobramentos: artigos em homenagem à professora Maria Celeste Consolin Dezotti. São Paulo: Cultura Acadêmica.

, Anise D'O. 2015c. Edição de traduções alinhadas do grego antigo e produção de texto digital em português em ambientes web providos pelos projetos Alpheios/Perseus. Relatório Final do Projeto CNPq- Edital Chamada MCTI/CNPq/MEC/CAPES No 18/2012-3 Processo n. 406845/2012-3: FCLAr/Araraquara, SP.

, Anise D’O. [prelo] Anotação de corpus do grego antigo: projeto de tradução alinhada, treebank e léxico grego- português em serviços web. In São Paulo: Cultura Acadêmica.

HARRINGTON, J. Matthew. 2013. Meaningful Distinctions: The Utility of Perseus Project Latin Treebanking Tools for Latin Research-Based Pedagogy. CAMWS: 109th annual meeting, Iowa City. April. Disponível on-line: http://www.camws.org/meeting/2013/files/abstracts/347.Meaningful\%20Distinctions.pd $\mathrm{f}$

J. M. 2014. Linking the Consumption and Production of Scholarship in Advanced Latin and Greek Instruction within the Perseids Platform. CAMWS: 110th annual meeting, Waco, April 2014. Disponível on-line: https://camws.org/meeting/2014/abstracts/panels/012.Perseids/Perseids.2.pdf

J. Matthew. 2016. Iterative morphosyntax. Treebanking pedagogy as an application of the experimental method from 1st semester to graduate level at Tufts University. In SunoikisisDC 2016 - 9th Common Session, March 30, 2016: Teaching Classics in the digital era: pedagogical and logistical issue (Ryan Fowler, Gwen Gruber, J. Matthew Harrington, and Kenny Morrell). Digital Humanities, Leipzig University. Disponível on-line: https://youtu.be/8K7kVrfdRXo?t=51m26s.

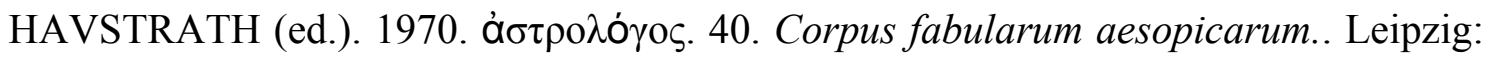
Bibliotheca Teubneriana.

LEE, John ; HUI, Ying Cheuk ; Kong, Yin Hei 2013. Treebanking for Data-driven Research in the Classroom. Proceedings of the Fourth Workshop on Teaching Natural Language Processing, p.56-60, Sofia, Bulgaria, August 4-9. Association for Computational Linguistics. Disponível on-line: http://www.aclweb.org/anthology/W13$\underline{3409}$

LIDDEL, H.G. \& Scott, R. 1940. A Greek-English Lexicon. revised and augmented throughout by. Sir Henry Stuart Jones. with the assistance of. Roderick McKenzie. Oxford. Clarendon Press. Disponível on-line: http://www.perseus.tufts.edu/hopper/text?doc=Perseus\%3Atext\%3A1999.04.0057\%3A entry $\% 3 \mathrm{De}) \% 2 \mathrm{Fqos}$. 
The ESPecialist: Descrição, Ensino e Aprendizagem, Vol. 38 No. 1 jan-jul 2017

https://revistas.pucsp.br/esp CThe ESPecialist

ISSN 2318-7115

SMYTH, Herbert Weir 1920. A Greek Grammar for Colleges. Cambridge, American Book Company. Disponível on-line http://www.perseus.tufts.edu/hopper/text?doc=Smyth\%20grammar\%201444\&lang=orig inal

TLG. 2016. Thesaurus Linguae Graecae. A Digital Library of Greek Literature. University of California Irvine. Acesso restrito on-line: http://www.tlg.uci.edu.

WORTHINGTON, R. (ed.).1884. Esop's Fables. New York: Frank F. Lovell.

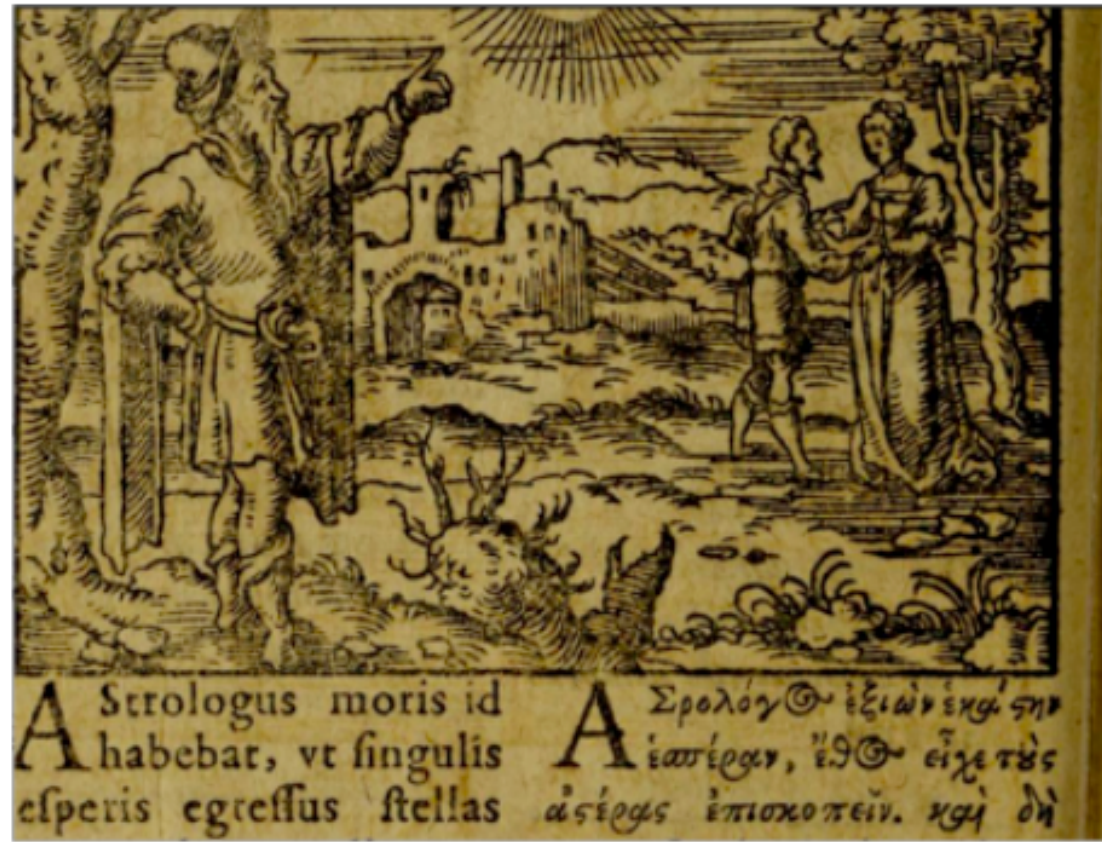

Recorte da ilustração da fábula do astrónomo da edição bilingue latim-grego de 1610 de Mythologia Aesopica, por Planudes, Maximus, ca. 1260-ca. 1310. p. 226 n. 169. Fonte: https: archive.org details mythologiasopica00plan

Anise D' Orange Ferreira is PhD in psychology and classics (Greek), participated in the Brazilian National Research and Educational Network Project from 1994 to 1997, and worked for ten years at PUCSP Graduate Program in Applied Linguistics and Language Studies, on projects in the Language, Education and Technology line of research. Since 2003 teaches Greek language at São Paulo State University (Unesp), School of Humanities and Sciences, Araraquara and since 2010 at its Graduate Program in Linguistics and Portuguese Language, supervising projects focused on online learning and digital technologies related to Humanities and Education. Her projects aim at producing open data, involving aligned translations, treebanking, and the annotation of the Greek-Portuguese Digital Dictionary. Affiliated with research groups ALTER-CNPq and Linceu. Member of ALTER-CNPq and LINCEU research groups, and since 2015 is a participant of the consortium SUNOIKISIS Digital Classics. E-mail: anise.a@gmail.com 